\title{
The Extent of Mathematics Teacher's Awareness of Their Students' Misconceptions in Learning Geometrical Concepts in the Intermediate Education Stage
}

\author{
Dr. Mohammad Ahmad Al-Khateeb \\ Associate Professor of Curricula \& Mathematics Teaching Methods, \\ College of Education, Taibah University, Saudi Arabia
}

doi: 10.19044/esj.2016.v12n31p357 URL:http://dx.doi.org/10.19044/esj.2016.v12n31p357

\begin{abstract}
This study aims to examine and highlight the extent of mathematics teacher's awareness of their student's geometrical misconceptions and mistakes in the intermediate education stage. The sample consisted of (400) first grade students and (40) teachers. The results showed that intermediate education stage students suffered from various geometrical misconceptions such as parallelogram, trapezoid, rhombus, etc. Additionally, the study spotlighted mathematics teachers' lack of awareness of their student's mistakes due to their poor introductory techniques, inability to put suitable instructional plans to teach geometrical concepts and analyze them into their sub-components, incapability to use various instructional methods to teach such concepts, and other negative factors. The study proposed some recommendation to benefit from by all concerned parties in the teachinglearning process to overcome students' geometrical misconceptions including educational planners, curricula authors, educational supervisors, and teachers. Finally, the study suggested some hints on future research in this field.
\end{abstract}

Keywords: Teacher's Awareness, Misconceptions, Mathematics

\section{Introduction}

Geometry is one of the most important facets of mathematics since it addresses subjects which are closely related to human's life and future. However, this science is conceptual in terms of its nature that underlies many concepts which represent the main bedrocks to comprehend the nature of this science. These concepts constitute a source of difficulty in the teachinglearning process. In addition, it is regarded as the most difficult topics in 
math for both teachers and learners as indicated and confirmed by a study conducted by Muschla (Muschla, 2002).

Due to the fact that the learning of geometrical concepts requires high mental ability that learner should acquire to be able to conceive, analyze them, as well as to recognize their relationships (Jacobson \& Lehrer, 2000), more attention, in recent years, has been given to learner's conceptual construct. It also studies what such construct includes in terms of incorrect perceptions or concepts. As a result, teachers face considerable challenge which is represented in helping learners in learning concepts soundly and to correct such incorrect concepts that are found in their cognitive construct (Chi, 2005). This would make it difficult for them to be ignored in the course of the teaching process. Therefore, the importance of teachers' awareness and recognition of conceptual mistakes made by their learners is embodied in learners' difficulties which in turn confuse their learning of such concepts (Lloyd, 2005). Incorrect concepts can be corrected through deliberate attempts and the use of modern teaching strategies and models to facilitate the transition process from the wrong to the right concept (Jones, 2000).

Consequently, the development of erroneous concepts phenomenon is well-known and well thought of by those working in the educational field. Thus, it was diagnosed by a number of prominent education and science scholars such as Bruner, Ausabel, Novak, and others. It has been recognized as the presence of learners' various misconceptions at different ages, and that building valid concepts instead of wrong ones has become one of the most vivid goals of education to ensure optimal utilization of those concepts. Here, numerous errors arose in the learners' concepts. Also, different educational levels and terminologies were used to express them such as wrong understanding, alternative understanding, preconceptions, and intuitive beliefs (Muschla, 2002).

It was recognized that if learners make mistakes in learning something, their subsequent learning will based on that error. Thus, this series of mistakes will lasts until learners' thinking become confused. Consequently, some of their findings and judgments on various things and phenomena were wrong. Thus, if we recognize this dilemma, we can understand how these dangerous misconceptions, their hazardous effects, will be maintained by the learners throughout their academic years without being corrected (Fujita \& Jones, 2007).

Subsequently, the diagnosis of geometrical misconceptions is surrounded by some of the difficulties since such misconceptions made by learners are varied. Some of these misconceptions result from the lack of prior knowledge of geometrical concept, including the errors that have been caused by learners' insufficient knowledge of the geometrical concept. Unlike what specialists think and this type of geometrical misconceptions, it 
was found that the learners showed resistance to correct them. They, however, contrasts the first and second types of previously mentioned geometrical misconceptions that can easily deal with learners so as to correct them (Nazario \& Burrowes, 2002).

Even after the diagnosis of geometrical misconceptions, how to deal with such misconceptions remains a burden that has to be incurred by those who are concerned with geometry teaching. Thus, this is because they cannot be easily corrected. However, there is still hope to discover the fixed causes of their effects in the learners' mind as well as the teacher's awareness, knowledge and familiarity with/of their students' geometrical misconceptions, and early detection of the reasons for occurrence in their students' minds (Groth, 2005).

The geometrical misconceptions and the risks which they cause to the learning process in the intermediate education stage are being represented by hindering students in this education stage who maintain such misconceptions. Also, their effect on student's performance levels academically includes the prolongation of their academic future which constitutes the study and the disclosure of such misconceptions. Also, it finds out the real reasons as well as the extent of teachers' awareness, knowledge familiarity with geometrical misconceptions, the basic bedrock to develop curriculum, and the choice of appropriate and effective teaching methods to ensure that students' geometrical misconceptions have been corrected. In addition, it avoids the occurrence of such misconceptions in the future (Muschla, 2002).

Through the field follow-up for two years, many of the intermediate school students' geometrical misconceptions have been observed when their teachers taught them some geometric concepts such as the parallelogram. The parallelogram is a polygon which has four sides. Rhombus is a parallelogram and one of its angles is a right angle. The two diameters of the rectangle are equal and perpendicular. However, these diameters divide each other equally which leads to confusion between the concepts of the square and rhombus. Therefore, the problem of the study can summed up in the diagnosis of the reality of the geometrical misconceptions among intermediate education students and their teachers' awareness and knowledge of these misconceptions, as well as the reasons for their occurrence.

In light of the indicators which refer to the first grades mathematic teachers' weakness in the field of training on detecting misconceptions that were revealed by some Arab studies in the first four grades (Driscoll, Egan, Dimatteo \& Nikula, 2009), the following questions appear in this context: What is the extent of mathematics teachers' awareness of their students' misconceptions? What is the extent of mathematics teachers' awareness of 
the way in which the process of learning these concepts occurred as well as their accompanied mental and performance processes? What are the forms of understanding and comprehension which result from them? Do mathematics teachers have the ability to choose the most appropriate strategies as well as do they consider new approaches and trends in teaching concepts for intermediate education students in general? Consequently, this study endeavors to answer some of the questions that many of those who are concerned with the teaching-learning process of the geometrical concepts pertain to the real status of teaching such concepts. It also involves the difficulties that are encountered and more relevant questions which still require answers and in-depth research.

\section{The Problem of the Study}

The problem of this study is represented in spotlighting the reasons behind intermediate education students' geometrical misconceptions. In the meantime, many mathematics teachers at this education stage don't recognize such misconceptions made by their students. Therefore, this study also tries to specify these mistakes as well as the extent of their teachers' awareness of such errors in a bid to ascertain their major reasons. Additionally, this study attempts to answer the following questions:

1. What are the geometrical misconceptions acquired by students of the intermediate education stage?

2. What is the extent of mathematics teachers' awareness of the geometrical misconceptions made by their students in learning geometry in the intermediate education stage?

3. What are the reasons behind student's geometrical misconceptions in the intermediate education stage?

\section{The Importance of the Study}

This study is very important because it offers assistance to all of those who are concerned with the teaching-learning process of geometrical concepts. Therefore, they include the following:

1. Students in the intermediate education stage through helping them to avoid having geometrical misconceptions which have considerable effect on their performance during their academic year which in turn prolong their academic future.

2. Mathematics Teachers in the intermediate education stage through recognizing their students' geometrical misconceptions and their reasons.

3. Curricula planners, developers, and authors of mathematics school textbooks through identifying geometrical misconceptions of students in the intermediate education stage as well as observing such misconceptions when 
selecting the contents of mathematics curricula and through reattempting to treat such contents to minimize the occurrence of such misconceptions.

\section{The Limitations of the Study}

This study is exclusively carried out to highlight the geometrical concepts included in the first grade's mathematics curriculum.

\section{The Terminologies of the Study Geometrical Misconceptions}

Geometrical misconceptions are the students' unacceptable explanations and responses about geometrical concepts as a result of passing through inaccurate, incorrect and confused life, and learning experiences which contradict with the approved geometrical concepts by mathematics teaching professionals partially or wholly. This is based on the fact that students' awareness of such concepts is in contrast with those who are specialized in these concepts. Geometrical misconceptions are specified by the diagnostic tests prepared for this purpose and applied on a sample of first grade students. Therefore, the geometrical concept is incorrect if the wrong answer to one of its components is more than forty-four percent (45\%) out of the total number of the students' diagnostic study sample.

\section{Misconceptions}

Mathematics Teachers' Awareness of their Student's Geometrical

Mathematics teachers' knowledge, understanding and familiarization with unacceptable information, perceptions, and explanations and answers provided by their students concerning wrong, inaccurate, and confused geometrical concepts contradicts partially or wholly with the mathematics teaching professionals' approved geometrical concepts. Here, students' awareness of such concepts is in contrast with those who are specialized in these concepts. Procedurally, these mistakes are measured by the score achieved by teacher in the awareness measurement of students' geometrical misconceptions in the intermediate education stage as well as the score achieved by the same teacher per sue its performance observation card when teaching geometrical concepts.

\section{The Procedures of the Study}

\section{The Methodology of the Study}

The descriptive and analytical methodology is used to spotlight the aim of this study. 


\section{The Sample of the Study}

\section{The Students' Sample in the Study}

The study sample consisted of four hundred (400) first grade students in the intermediate education stage who were distributed over ten (10) public schools of the education district in the city of Al-Madina Al-Monawara in the Kingdom of Saudi Arabia. The study sample was approved as mentioned earlier since those students in the intermediate education stage studied all of the geometrical concepts which constituted the pivot of the study focus.

\section{The Teachers' Sample in the Study}

The study sample consisted of fifty (50) teachers who taught mathematics to students in the intermediate education stage and who were distributed over twenty-five (25) public schools of the education district in the city of AlMadina Al-Monawara in the Kingdom of Saudi Arabia.

\section{The Instruments of the Study}

Consequently, the following instruments were used in this study:

\section{First - The Diagnostic Test}

A diagnostic test was prepared for the geometrical concepts. In addition, this test was verified to ensure its validity and reliability in order to apply it on a sample of first grade students in the intermediate education stage.

Second - Preparation of a Measurement to Evaluate Mathematics Teachers' Awareness of their Student's Geometrical Misconceptions

This measurement aimed to evaluate the extent of mathematics teachers' awareness of their students' geometrical misconceptions which consisted of fifty-six items. However, it was constructed based on the evaluation forms and the diagnosis of conceptual mistakes, mainly; Davis Model, Frayer Model, and Mastery Learning Model of Concepts. This measurement was verified to ensure its validity and reliability.

\section{Third - Teachers' Performance Observation Card when Teaching Geometrical Concepts}

This performance observation card consisted of twenty (20) class practices relevant to mathematics teachers' awareness of geometrical misconceptions. However, it was constructed based on the aforementioned evaluation forms and the diagnosis of conceptual mistakes. Also, it was prepared to monitor teachers' teaching behavior inside the classroom through the implementation of geometry lesson. This instrument was verified to ensure its validity and reliability. 


\section{Results and Discussion of the Study}

The Results and Discussion of the First Question: "What are the geometrical misconceptions made by students of the intermediate education stage?"

In answering this question, the diagnostic test of geometrical concepts was applied on a sample four hundred (400) first grade students from a number of schools to determine their geometrical misconceptions. The data obtained from the test were emptied, and a list of these geometrical misconceptions and mistakes was prepared. Also, the percentage of their occurrence in accordance with the procedural definition of the geometrical misconception is illustrated in the following table:

\section{First Grade Students' Geometrical Misconceptions in the Intermediate Education Stage}

\begin{tabular}{|c|c|c|}
\hline No. & Concept & Misconception \\
\hline & Parallelogram & The student doesn't recognize that the rectangular is a sub-concept of parallelogram. \\
\hline & Trapezoid & The student doesn't recognize that each trapezoid is a polygon. \\
\hline & \multirow[t]{2}{*}{ Rhombus } & $\begin{array}{l}\text { The student doesn't recognize that all rhombus forms have four angles and each two } \\
\text { opposite angles are equal. }\end{array}$ \\
\hline & & $\begin{array}{l}\text { The student doesn't recognize that the characteristics of rhombus in all of its cases } \\
\text { don't have four right angles when the rhombus is a square. }\end{array}$ \\
\hline & \multirow[t]{2}{*}{ Reflection } & $\begin{array}{l}\text { The student doesn't recognize that the characteristics of reflections include the } \\
\text { following: maintaining the measures of angles, the measurements of lengths, and } \\
\text { reflecting the rotational direction. }\end{array}$ \\
\hline & & The student doesn't recognize that reflection doesn't maintain the rotational direction. \\
\hline & \multirow[t]{4}{*}{ Rotation } & $\begin{array}{l}\text { The student doesn't recognize that rotation doesn't cause the rotation of the shape; } \\
\text { alongside, it doesn't keep the measurements of angles. }\end{array}$ \\
\hline & & $\begin{array}{l}\text { The student doesn't recognize that rotation is geometrical transformation which } \\
\text { transforms every point of the form into another point with another specific angle and } \\
\text { direction around a fixed point. }\end{array}$ \\
\hline & & The student doesn't recognize that rotation is geometrical transformation. \\
\hline & & $\begin{array}{l}\text { The student doesn't recognize that the characteristics of rotation include the } \\
\text { following: maintaining parallel, lengths, and rotational direction. }\end{array}$ \\
\hline & \multirow[t]{4}{*}{ Translation } & $\begin{array}{l}\text { The student doesn't recognize that the translation of the shape doesn't cause the } \\
\text { keeping of directions and distance. }\end{array}$ \\
\hline & & $\begin{array}{l}\text { The student doesn't recognize that the translation of the shape is the geometric } \\
\text { transformation which moves all the points of the shape which have equal distances } \\
\text { and are in the same direction. }\end{array}$ \\
\hline & & The student doesn't recognize that the translation is a geometric transformation. \\
\hline & & The student doesn't recognize all the types of translations. \\
\hline & \multirow[t]{4}{*}{ Homology } & $\begin{array}{l}\text { The student doesn't recognize that the homology of any geometrical shape doesn't } \\
\text { cause dissimilarity of two congruent shapes. }\end{array}$ \\
\hline & & $\begin{array}{c}\text { The student doesn't recognize that the homology is represented in the following: } \\
\text { closed shapes that are congruent with each other when classifying them around an } \\
\text { axis. }\end{array}$ \\
\hline & & The student doesn't recognize that the homology is congruence. \\
\hline & & $\begin{array}{l}\text { The student doesn't recognize that one homology characteristics is keeping the } \\
\text { distance between two points in any closed shape. }\end{array}$ \\
\hline & Triangle & $\begin{array}{l}\text { The student doesn't recognize that the triangle doesn't, in all of its cases, have three } \\
\text { acute angles. }\end{array}$ \\
\hline
\end{tabular}


The abovementioned table indicated that first grade students have various mistakes which were classified as geometrical misconceptions. In addition, they lacked the ability to understand such concepts. Therefore, the misconceptions can be spotlighted in detail as follows:

\section{One - The Concept of Parallelogram}

When students were given the name of the concept, they could choose one of its sub-concepts. Surprisingly, $82.8 \%$ of the students' sample failed to realize that the rectangular is a sub-concept of the parallelogram.

\section{Two - The Concept of Trapezoid}

It was expected that when students were given the name of the concept, they could choose one of its main concepts. However, 58.3\% of the students' sample failed to realize that every trapezoid is a parallelogram.

\section{Three - The Concept of Rhombus}

It was expected that when students were given the name of the concept, they could choose its values. However, 58.3\% of the students' sample failed to realize that all rhombus forms had four angles and each two opposite angles were equal. When they were given the name of the concept, they could choose its irrelevant characteristics. However, 56\% of them didn't succeed to recognize that the rhombus didn't always have four right angles when it took the form of a square.

\section{Four - The Concept of Reflection}

It was expected that when students were given the name of the concept, they could choose its characteristics. However, $73.5 \%$ of the students' sample failed to realize that the characteristics of reflection encompassed the maintaining of angles and lengths measurements. Also, $68.3 \%$ of them failed to choose its irrelevant characteristics and it shows that it didn't keep the rotational direction.

\section{Five - The Concept of Rotation}

It was expected that when students were given the name of the concept, they could choose the characteristics of rotation concept. However, $57.8 \%$ of the students' sample failed to realize that the characteristics of rotation encompassed the maintaining of the measurements angles and lengths and the rotational direction. 55.3\% of them failed to choose its irrelevant characteristics represented in that rotation didn't occur for the shape along with not keeping the measurements of the angles. It was expected that when they were given the name of the concept, they could choose its correct definition. However, $64.8 \%$ of them failed to recognize 
that rotation was the geometric transformation which transformed each point of the shape into another point with certain angle and direction around a fixed point. When students were given the name of the concept, it was expected from them to choose one of its main concepts. $51 \%$ of them failed to realize that rotation is a geometric transformation. When they were given the name of the concept, they accepted one of its sub-concepts. In addition, $51 \%$ of them failed to recognize all the types of rotation.

\section{Six - The Concept of Translation}

It was expected that when students were given the name of the concept, they could choose the irrelevant characteristics of translation concept. However, $48.8 \%$ of the students' sample failed to realize that the translation of a shape didn't cause the lack of maintaining the rotational directions and the measurements of lengths. Also, when they were given the name of the concept, it was expected from them to choose its correct definitions. Thus, $67.2 \%$ of them were unable to realize that the concept of translation was the geometric transformation which transferred all points of the shape in equal distances and in the same direction. When students were asked to choose one of its basic concepts, 56\% of them didn't succeed to realize that translation was geometric transformation. When they were given the name of this concept, it was expected that they could choose one of its sub-concepts. However, 54.2\% of them failed to recognize all the types of translation.

\section{Seven - The Concept of Homology}

It was expected that when students were given the name of the homology concept, they could choose its characteristics. 55.5\% failed to recognize that one of those characteristics was the keeping of the distance between two points in any closed shape. It was also expected that when students were given the name of the concept, they could choose the characteristics of homology concept. 63.5\% of the students' sample failed to realize that the homology of any shape didn't cause dissimilarity of two shapes. When they were given the name of the concept, it was expected that they could choose its correct definition. However, 64.3\% of them failed to recognize that homology was represented in closed shapes which were accorded with each other when they were classified around an axis. When students were asked to choose one of its basic concepts, 63.8\% of them didn't succeed to realize that homology was congruence. When they were given the name of this concept, it was expected that they could choose one of its subconcepts. However, 63.8\% of them failed to recognize all types of homology. 


\section{Seven - The Concept of the Triangle}

It was expected that when students were given the name of the triangle concept, they could choose its irrelevant characteristics. However, $60 \%$ failed to recognize that one of those characteristics was that the triangle didn't always have three acute angles.

The Results and Discussion of the Second Question: "What is the extent of mathematics teachers' awareness of the geometrical misconceptions made by their students in learning geometry in the intermediate education stage?

To answer this question, the following steps were taken:

\section{First - The measurement of the extent of the intermediate education stage teachers' awareness of their students' misconceptions in learning geometry.}

This measurement was applied and the percentages of the sample individuals were extracted for each item of the measurement. Subsequently, the incongruity percentage of the measurement items ranged between $51 \%$ $97 \%$, and the incongruity of each item was higher than frequency and congruity. Through calculating the chi-square of the previous items, it was shown that all of them were statistically significant at 0.001 for the benefit of incongruity. In general, mathematics teachers in the intermediate education stage lacked awareness of their students' misconceptions in learning geometry since incongruity percentage of each item was more than $50 \%$.

\section{Second - Teachers' observation card was applied}

The percentages of the correct answers were extracted for each item of the observation card of mathematics teachers in the intermediate education stage while teaching geometrical concepts. Therefore, the results revealed statistical significance due to the availability of 13 indicators out of 20 which scored "weak." Also, 5 out of 20 indicators also demonstrated statistical significance which scored "good." Finally, 2 out of 20 indicators didn't show statistical significance (items 4 \& 5).

The results obtained from the mathematics teachers' observation card revealed that they were unable to put suitable instruction plan to teach geometrical concepts. Also, they were not capable of analyzing geometrical concepts into their components and sub-components, and they didn't have the ability to explain each of their components separately. However, the aforementioned mathematics teachers' inability contradicted the relevant international standard which it was accorded with (NCTM, 2008). Mathematics teachers' use of various geometrical concepts teaching strategies, use of relevant students' evaluation behaviors pertained to 
geometrical concepts, as well as the ability to formulate and direct probing questions during teaching such concepts were weak. Mathematics teachers lacked the ability to focus on detecting the presence of students' geometrical misconceptions. In addition, they are able to define the reasons for the occurrence and existence of such misconceptions. Therefore, they had to apply new teaching methods which were accorded with the study conducted by

\section{Nazario \& Burrowes (2002).}

In considering teachers' answers included in the study sample concerning the indicators of geometrical misconceptions through the designated measurement and observation card, it was observed that there was a disparity in the degree of awareness among them. In general, it was low and below expectation. Thus, the decline in the degree of awareness will negatively affect the teaching practices inside the classroom which may be attributed to the specific training and supervision programs prepared for the category of class teachers. Thus, these teachers lack interest in explaining the processes and basic teaching methods. Instead, these programs focused on providing prescription that consists of various procedures to be followed by teachers during their teaching process. It is also expected that such a situation ascertains teachers' attention on outcomes rather than operations. Thus, this affects teachers' diagnose of their students' learning problems as well as their ability to innovate new and extraordinary correction and diagnostic methods. Results of measurement and observation card have supported the discussions with a number of teachers on some geometrical misconceptions and mistakes. Also, various processes and treatments pertain to the teaching-learning process of geometrical concepts since out of the majority of those interviewed, seven teachers were not aware of the ways and methods of detecting and dealing with geometric misconceptions. None of the teachers referred to the utilization of analyzing the mathematical concept into its components during the preparation of their teaching implementation plans which is in accordance with the study conducted by Ball, Hill \& Bass (2005). Thus, their study show that mathematics teacher of first grades don't receive any training oriented mainly to deal with many necessary processes and treatments to teach mathematical concepts as well as to treat their students' misconceptions. This is done either by the educational supervisors who follow them up or the concerned parties which are responsible for the preparation and implementation of in-service teachers' training programs. 
The Results and Discussion of the Third Question: "What are the reasons behind student's geometrical misconceptions in the intermediate education stage?

This question was answered by conducting a critical reading of teachers' and students' answers about the study instruments. Also, the reasons behind students' geometrical misconceptions were summarized as follows:

\section{Reasons Related to Teachers}

1) Teachers' Poor Introduction of the Lesson Introducing the lesson is not a practical matter, but it is a behavior made by the teachers when entering the classroom to prepare their students' minds to be ready to receive their new lesson eagerly and interestingly.

There are general and specific introductions. General introduction may take the form of slight joke that make students feel happy and open their minds before the lesson starts. It can also be made by asking about a student who is absent due to his illness along with urging students to visit him and inform him about his teacher's wishes to recover from his illness speedily. In general, such introduction shall not transcend a minute.

Subsequently, the specific introduction introduces the topic of the lesson through displaying attractive images or relevant story of the lesson, exciting summary, or through linking the topic of the lesson with students' real life. This makes them feel they are interested. Therefore, they become very desirous to learn the lesson, or through asking a number of questions about the previous lesson, in order to move to the new lesson gradually so that the introduction constitutes a connecting link between the previous and the new lessons.

2) Teachers' inability to prepare suitable instructional plan to teach geometrical concepts, incapable of analyzing the geometrical concepts into their main and sub-contents, and they are not able to use various teaching strategies that pertains to geometrical concepts.

3) Teachers don't use appropriate evaluation behaviors concerning their students' academic achievement in the field of learning geometrical concepts, and they don't have the skills to formulate and direct probing questions during teaching geometrical concepts. In addition, they are unable to detect their students' geometrical concepts on a permanent basis.

4) Teachers are not able to define the reason behind geometrical concepts formation and prevalence among their students, and they are also unable to use geometrical communication language when teaching such concepts. Additionally, teachers can't provide remedial activities for students who suffer from weaknesses in learning geometrical concepts. However, these results are accorded with a number of studies (Barrantes \& Blanco, 2006; Bolte, 2001). 


\section{Reasons Related to Students}

Consequently, the following reasons were observed through analyzing the results of the diagnostic test which were represented in their inability to define the following when they were given the name of the concept:

1. The concept and its sub-concept

2. The basic concept

3. The characteristics of the concept

4. The irrelevant characteristics of the concept

5. The correct definition of the concept

\section{Recommendations}

In light of the abovementioned study results, the following recommendations were given:

- $\quad$ Preparing and conducting high level training programs for trainers, educational supervisors, and teachers in the field of teaching mathematical concepts and analyzing them into their respective components and subcomponents.

- Giving more attention to mathematical content authoring which is related to various concepts, and subjecting them to accurate reviews which transcend the limits of language and printing errors.

- $\quad$ Constructing grade-level tests to detect learners' misconceptions in the pre-tertiary education.

- $\quad$ Increasing the use of concept changing strategies as well as training of teacher of grades in the intermediate education stage.

- Conducting intensive training and specialized courses in misconceptions to all those who are concerned with the teaching-learning process including mathematics teachers, members of curricula authoring, and educational supervisors. This would help to deepen their awareness of the nature, ways of misconceptions occurrence, the existing natural relationship among them, as well as recognizing the theoretical trends and models which explain and remedy misconceptions by considering them as a complex mental and cognitive performance.

\section{Suggestions for Future Research}

The real value of scientific research doesn't only entail the solution of the study problem, but it also concentrates on spotlighting new researchworthy problems. However, this study stressed the need to carry out the following studies in the future:

- $\quad$ Examining and studying students' mathematical misconceptions in various education stages as well as their teachers' awareness of such misconceptions. 
- $\quad$ Studying the effectiveness of mathematical concepts teaching by using various teaching models and strategies including Frayer Model as well as other models which based on analyzing the concept into its basic contents and sub-contents in order to correct learners' mathematical misconceptions.

\section{References:}

1. Al - Qurashi, F. (2002). An Investigation of the Role of Inquiry Based Instruction in Mathematics Teacher Professional Development Activities and Outcomes of an Inquiry Based Instruction Project, PhD, Ohio University.

2. Blanco, L., and Garrote, M. (2007). Difficulties in learning inequalities in students of the first year of pre-university education in Spain. Eurasia Journal of Mathematics, Science and Technology Education, 3, 221-229.

3. Ball, D., Hill, H., and Bass, H. (2005). Knowing mathematics for teaching: Who knows mathematics well enough to teach third grade, and how can we decide? American Educator, 14-22, 43-46.

4. Barcellos, A. (2005). Mathematics misconceptions of college-age algebra students. Unpublished doctoral dissertation, University of California, Davis.

5. Barrantes, M. and Blanco, L. (2006). A study of prospective primary teacher's conceptions of teaching and learning school geometry. Journal of Mathematics Teacher Education, 9, 411-436.

6. Bolte, L. (2001). Mathematical Essays: An Alternate View of Students Knowledge. In C. Duke and R. Sanchez (Eds), Assessing Writing Across the Curriculum (pp. 146- 162). Durham, NC: Carolina Academic press

7. Bush, B., Ronau, B., Moody, M. and McGatha, M. (2006). What we know about middle school teachers' knowledge of mathematics. Presentation at the annual meeting of National Council of Teachers of Mathematics. St. Louis, MO.

8. Chi, M. (2005). Commonsense conceptions of emergent process: Why some misconceptions are robust. The Journal of the Learning Science, 14, 161-199.

9. Chi, M. and Roscoe, R. (2002). The processes and challenges of conceptual change. In M. Limon and L. Mason (Eds.), Reforming the process of conceptual change: Integrating theory and practice (pp. 3-27), Dordrecht, The Netherlands: Kluwer Academic.

10. Dreyfus, A. Jungwirth, E. and Eliovitch, R. (1990). Applying the Cognitive Conflict for Conceptual Change-Some Implications, Difficulties, and Problems. Science Education. 
11. Driscoll, M., Egan, M., Dimatteo, R. W. and Nikula, J. (2009). Fostering geometric thinking in the middle grades: Professional development for teachers in grades 5-10. In T. V. Craine and R. Rubenstein (Eds) Understanding geometry for a changing world: Seventy-first yearbook (pp. 155-171). Reston, VA: National Council of Teachers of Mathematics

12. Frayer, D.(1970) "Effects of Number of Instances And Emphasis of Relevant Attribute Values on Mastery of Geometric By Fourth And Sixth Grade Child", Madsion: Wissconsion Research And Development Center for Cognitive Learning, Tech. Rer. No. 116.

13. Frayer, D. And Other.(1969) "Aschema For Testing The Level of Concept Mastery", Madsion: Wissconsion Research And Development Center for Cognitive Learning, Working Pope, No. 16.

14. Fujita T. and Jones, K. (2006). Primary trainee teachers' understanding of basic geometrical figures in Scotland. In $\mathrm{H}$. Moraova, M. Kratka, N. Stehlikova (Eds.) Proceedings 30th Conference of the International Group for Psychology of Mathematics Education, Prague, Vol. 3, 129-136.

15. Fujita T. and Jones, K. (2007). Learners' understanding of the definitions and hierarchical classification of quadrilaterals: Towards a theoretical framing, Research in Mathematics Education, 9(1-2), 320

16. Groth, R. (2005). Linking theory and practice in teaching geometry. Mathematics Teacher, 99 (1), 27-30.

17. Hill, H., Sleep, L., Lewis, J. and Ball, D. (2008). Assessing teachers' mathematical knowledge: What knowledge matters and what evidence counts? In F. K. Lester (Ed.), Second Handbook of Research on Mathematics Teaching and Learning (pp. 111-155). Charlotte, NC: Information Age Publishing.

18. Kajander, M., (2007), Describing mathematics teacher growth, Presentation to the Education Forum of the Fields Institute for Mathematical Sciences, University of Toronto, Toronto.

19. Jacobson, C. and Lehrer, R. (2000). Teacher appropriation and student learning of geometry through design. Journal for Research in Mathematics Education, 31(1), 71-88.

20. Jendraszek, P. (2008). Misconceptions of probability among future teachers of mathematics. Dissertation Abstracts International-A, 69(01), 2008. (UMI No. AAT 3299270

21. Jones, K. (2000). Teacher Knowledge and professional development in geometry. Proceedings of the British Society for Research into Learning Mathematics, 20(3), 109-114. 
22. Learning Mathematics for Teaching Project. (2009). Measures of teachers' knowledge for teaching mathematics. Ann Arbor, MI: University of Michigan. Retrieved June 23, 2012, from http://sitemaker.umich.edu/lmt/home

23. Lloyd, G. (2005). Beliefs about the teacher's role in the mathematics classroom: One student teacher's explorations in fiction and in practice. Journal of Mathematics Teacher Education, 8(6), 441467.

24. Lynn, H. (2002), Pre-service Teachers Beliefs and Practice After Participating in an Integrated Content / Methods Course, School Science and Mathematics, 102(1): $4-11$.

25. Muschla, J. (2002). Geometry teacher's activities kit: ready-to-use lessons \& worksheets for grades 6-12. West Nyack, NY: Center for Applied Research in Education

26. National Council of Teachers of Mathematics. (2006). Curriculum focal points for prekindergarten through grade 8 mathematics: A quest for coherence. Reston, VA: National Council of Teachers of Mathematics.

27. National Council of Teachers of Mathematics. (2006). Learning from NAEP: Professional Development Materials for Teachers of Mathematics. Reston, VA:

28. National Council of Teachers of Mathematics. The National Mathematics Advisory Panel. (2008). Foundation for success: The final report of National Advisory Panel. Retrieved on July 23, 2012 from

29. http://www.ed.gov/about/bdscomm/list/mathpanel/report/finalreport.pdf

30. Nazario, G. and Burrowes, P. (2002). Persisting misconceptions, Journal of college science teaching.

31. Paniati, J. (2009). Teaching geometry for conceptual understanding: One teacher's perspective. In T.V. Craine and R. Rubenstein (Eds) Understanding geometry for a changing world: Seventy-first yearbook (pp. 175-188). Reston, VA: National Council of Teachers of Mathematics.

32. Robinson. M. (2003). The effect of standards - based professional development participation on the teaching of mathematics at two - year colleges in New Mexico, PhD, the University of New Mexico. 